\title{
Abstract
}

The placenta and tumors share important characteristics, including a requirement to establish effective angiogenesis. In the case of the placenta, optimal angiogenesis is required to sustain the blood flow required to maintain a successful pregnancy, whereas in tumors establishing new blood supplies is considered a key step in supporting metastases. Therefore the development of novel angiogenesis inhibitors has been an area of active research in oncology. A subset of the molecular processes regulating angiogenesis are well understood in the context of both early placentation and tumorigenesis. In this review we focus on the well-established role of androgen regulation of angiogenesis in cancer and relate these mechanisms to placental angiogenesis. The physiological actions of androgens are mediated by the androgen receptor (AR), a ligand dependent transcription factor. Androgens and the AR are essential for normal male embryonic development, puberty and lifelong health. Defects in androgen signalling are associated with a diverse range of clinical disorders in men and women including disorders of sex development (DSD), polycystic ovary syndrome in women and many cancers. We summarize the diverse molecular mechanisms of androgen regulation of angiogenesis and infer the potential significance of these pathways to normal and pathogenic placental function. Finally, we offer potential research applications of androgen-targeting molecules developed to treat cancer as investigative tools to help further delineate the role of androgen signalling in placental function and maternal and offspring health in animal models. 



\section{Androgen dependent mechanisms of pro-angiogenic networks in placental and tumor development}

Veronika M. Metzler ${ }^{1}$, Simone de Brot ${ }^{1}$, Robert S. Robinson ${ }^{1}$, Jennie N. Jeyapalan ${ }^{1}$, Emad Rakha $^{2}$, Thomas Walton ${ }^{3}$, David S. Gardner', Emma Lund ${ }^{1}$, Jonathan Whitchurch ${ }^{4}$, Daisy Haigh $^{1}$, Jack M. Lochray ${ }^{1}$, Brian D. Robinson ${ }^{5}$, Cinzia Allegrucci ${ }^{1}$, Rupert G. Fray ${ }^{6}$, Jenny L. Persson $^{7,8}$, Niels $\varnothing$ dum $^{9}$, Regina R. Miftakhova ${ }^{8,10}$, Albert A. Rizvanov ${ }^{10}$, leuan A. Hughes ${ }^{11}$, Rieko Tadokoro-Cuccaro ${ }^{11}$, David M. Heery ${ }^{4}$, Catrin S. Rutland ${ }^{1 *}$ and Nigel P. Mongan ${ }^{1,12^{*}}$

${ }^{1}$ Faculty of Medicine and Health Sciences, School of Veterinary Medicine and Health Sciences, University of Nottingham, LE12 5RD, UK; ${ }^{2}$ School of Medicine and Sciences, University of Nottingham, Nottingham City Hospital, NG5 1PB, UK; ${ }^{3}$ Department of Urology, Nottingham University Hospitals NHS Trust, NG5 1PB, UK; ${ }^{4}$ School of Pharmacy, University of Nottingham, NG7 2TQ, UK; ${ }^{5}$ Department of Pathology, Weill Cornell Medicine, New York, 10065, USA; ${ }^{6}$ School of Biosciences, University of Nottingham, LE12 5RD, UK; ${ }^{7}$ Department of Translational Medicine, Lund University, Malmö, Sweden; ${ }^{8}$ Department of Molecular Biology, Umeå University, Sweden and ${ }^{9}$ Department of Immunology and Microbiology, University of Copenhagen, Denmark; ${ }^{10}$ Kazan Federal University, Kazan, Republic of Tatarstan, 420008, Russian Federation; ${ }^{11}$ Department of Paediatrics, University of Cambridge, Hills Rd, Cambridge, CB2 0QQ, UK; ; ${ }^{12}$ epartment of Pharmacology, Weill Cornell Medicine, New York, 10065, USA.

* authors for correspondence:

Dr. Nigel P. Mongan Dr. Catrin S. Rutland

Nigel.mongan@nottingham.ac.uk $\quad \underline{\text { Catrin.rutland@nottingham.ac.uk }}$

Tel: +44 1159516625

Tel: 441159516573 

- The placenta and tumors share important characteristics, including a requirement to establish effective angiogenesis.

- We focus on the well-established role of androgen regulation of angiogenesis in cancer and infer potential relevance to placental development and function. 


\section{Introduction}

2 It has long been recognized that the placenta and tumors share important characteristics. These

3 include mechanisms related to immune privilege and most notably in the context of this review,

4 a requirement to establish effective neovascularization and angiogenesis. Placental

5 angiogenesis is a tightly regulated process involving complex interactions of pro- and anti-

6 angiogenic factors, which if dysregulated can lead to different pregnancy complications

7 including preeclampsia [1]. Examples of important pro-angiogenic factors in the placenta include vascular endothelial growth factor (VEGF), placental growth factor (PIGF) and fibroblast growth factor (FGF) [2], whereas soluble fms-like tyrosine kinase 1 (sFlt-1) is noted as a key antiangiogenic factor [3]. A better understanding of placental angiogenesis would be beneficial in

11 understanding pathological conditions such as preeclampsia and intrauterine growth restriction.

12 This review will provide a summary of current understanding of the role of angiogenesis in cancer and placental physiology, with an emphasis on androgen regulation of pro-angiogenesis

14 pathways.

15 Androgens have long been known to play essential roles in male embryonic development and 16 pubertal maturation [4] and are now recognized as having a role in angiogenesis [reviewed in 5].

17 The most abundant physiological androgens in men are testosterone and its more potent derivative $5 \alpha$-dihydrotestosterone (DHT) which is produced by steroid-5a-reductase enzymes [6]. Testosterone can also be converted to the primary estrogen ( $\beta$-estradiol) by aromatase [7], therefore it is often essential to consider the relative roles of androgen and estrogen signalling. Androgen production is regulated in the hypothalamus, where gonadotrophin hormone-releasing

22 hormone $(\mathrm{GnRH})$ triggers the release of luteinizing hormone $(\mathrm{LH})$ from the pituitary gland [8]. $\mathrm{LH}$

23 in turn acts on the testes where the majority of the testosterone is synthesized. Testosterone is 24 transported to target tissues primarily bound to the sex hormone-binding globulin or to albumin $25[9,10]$. Secondary androgens, such as androstenedione (AED) and dehydroepiandrostenedione 
26 (DHEA) are produced primarily by the adrenal glands [8]. As we will discuss in detail later, there

27 is also evidence of androgen synthesis [11] and androgen receptor (AR) expression in the 28 placenta and endometrium [12-14].

\section{Androgen receptor signalling}

31 The actions of androgens are mediated primarily by the AR, also referred to as NR3C4 [15]. The

32 AR is a member of the ligand dependent superfamily of nuclear receptor transcription factors

33 which, in the presence of androgens, regulates the transcription of target genes [15]. Nuclear

34 receptors consist of three major domains: the N-terminal region, the DNA-binding domain (DBD)

35 and the C-terminal ligand-binding domain (LBD) [16]. The N-terminal region is variable in both

36 sequence and size and in the AR harbors an agonist independent transcriptional activation

37 function (AF-1) [17]. The highly conserved DBD is situated in the centre of the polypeptide and selectively and preferentially binds to androgen response elements in the regulatory regions of androgen target genes. The DBD and LBD are separated through a variable hinge region that contains DNA minor-groove binding residues [18]. The LBD is the site where both ligands and coregulators bind and where the second transcriptional activation function (AF-2) region is situated. In contrast to AF-1, AF-2 is ligand-dependent and full transcriptional activity can only be accomplished when AF-1 and AF-2 act together [19]. The AR regulates gene expression by recruiting multiple epigenetic coregulators, often through a conserved LxxLL motif, which control transcription via covalent histone modifications (Figure 1) [20]. The role of coregulators in gene activation and how these relate to the modulation of histone lysine acetylation and methylation is an area of active research. Nuclear receptor-coregulator complexes, and by inference the ARcoregulator complex, are believed to be dynamic [21] and involve the recruitment of diverse enzymes which covalently modify the N-terminal tail of histones such as lysine 
51 demethylases (KDMs), kinases/phosphatases, poly(ADP)ribosylases and ubiquitin ligases [22].

52 KATs and HDACs have been intensively studied and the general paradigm is that KAT activity

53 increases DNA accessibility, thus activating gene transcription, whereas HDACs are associated

54 with transcriptional repression $[23,24]$. It is important to note that certain coregulators, including

55 KDM1A which is also expressed in the placenta [25], can exhibit transcriptional activation and

56 repression properties in a cellular and epigenomic context-dependent manner [26].

\section{Androgens and fetal development}

59 During normal embryonic development and sex determination, the 46XY fetus instructs the 60 primitive bipotential gonad to develop into testes [4]. Testicular androgen production and the 61 ability to respond to these androgenic hormones are both then required to enable the $X Y$ fetus

62 to complete male sex differentiation [4 and references therein]. Yet, it is estimated that between

631 in 20,400 and 1 in 99,100 infants are unable to respond to androgens and present with complete $46 \mathrm{XY}$ sex reversal, termed complete androgen insensitivity [4]. Complete androgen insensitivity syndrome (CAIS) results in 46XY sex reversal and typically presents with pubertal amenorrhea or inguinal swelling in infants [27]. About $90-95 \%$ of all CAIS cases show mutations

67 in the AR causing hormone resistance [28]. Partial androgen insensitivity syndrome (PAIS) is more common and the PAIS phenotype is much more complex and diverse [4]. We [29-32] and others [33] have identified and functionally characterized numerous loss of function and intronic mutations in the $A R$ locus in individuals with complete and partial AIS. As we will explore in

71 more detail later, the inability of the CAIS fetus and the fetal placenta component to respond to 72 androgens suggests that pregnancy is sufficiently sustained by the ability of the maternal 73 placental component to respond to androgens. 
Androgens, angiogenesis and cancer

77 Much of our understanding of androgen regulation of angiogenesis has been obtained in cancer studies. Androgens and androgen signalling are implicated in many human cancer types, including prostate [34, 35], testicular germ cell [36] and bladder [37] cancers. Androgens are also known to have complex roles in breast tumors [38-40]. AR coregulators, including the

81 lysine demethylase KDM1A/LSD1 [37, 41, 42] and p160 coactivators [43-45] have also been

82 implicated in cancer, most notably prostate cancer (PCa). PCa is the most common noncutaneous cancer affecting men [46]. The treatment options for PCa are often dependent upon the age and general health of the patient, as well as the stage and grade of the cancer. Watchful waiting, active surveillance, radical prostatectomy and radiotherapy remain the most effective initial therapies of localized $\mathrm{PCa}$, however these can be associated with negative 87 impacts on quality of life $[47,48]$ and post-treatment recurrence remains common [49]. In the case of $\mathrm{PCa}$, treatments which block androgen biosynthesis or signalling, so called androgen selective antagonists (bicalutamide, enzalutamide) or blocking intra-tumoral androgen biosynthesis (abiraterone) [50,51]. Unfortunately, ADTs are ineffective in the long term for many patients, as incurable hormone refractory PCa tumors which are resistant to ADTs, commonly emerge within $\sim 18$ months at which point only palliative treatments are available. For this reason, great effort was invested to develop novel therapies targeting tumor angiogenesis. Indeed >20 years ago, Marshall and Narayan suggested a role for androgens in PCa

97 angiogenesis [52]. Subsequent studies in mouse PCa xenograft models indicated castration decreased angiogenesis with a concomitant decrease in levels of vascular endothelial growth factor A (VEGFA)[53]. More recently, we and others found that androgens and AR-coregulators 
regulate VEGFA levels (Figure 3) [35, 54, 55]. Consistent with this there is clinical [54] and genetic [56] evidence suggesting a link between VEGFA expression and poorer outcomes in PCa patients. Androgen depletion has been found to significantly induce apoptosis of tumor associated endothelial cells, suggesting a direct effect on angiogenesis, independent of the effect of androgen withdrawal on PCa cell proliferation and/or viability [53]. For these reasons there was much hope for treatments targeting pro-angiogenesis mediators such as VEGFA. However, clinical trials of angiogenesis inhibitors have been disappointing with only modest antitumor activity achieved in patients [57], though the use of anti-VEGFA therapy in combination with other agents shows more promise $[58,59]$.

\section{Androgens and angiogenesis in endometrial and placental function}

There is robust $A R$ expression in the endometrium $[13,60]$ and both the $A R$ and dihydrotestosterone are implicated in endometrial cancer. There is also evidence of endometrial and placental androgen biosynthesis $[11,12]$. However the expression of $A R$ in the placenta is controversial [14, 60-62]. In normal pregnancy, circulating androgen levels generally increase, compared with non-pregnant female hormone levels. Testosterone has been shown to increase by day 15 after the luteinizing hormone surge with reports of $\sim 1.55-1.7$ fold average increase from day 15 through to week 33 in comparison to non-pregnant women, changes were not observed prior to day $13[63,64]$. Androstenedioine levels rise from day 14 and increase on average by 1.3 fold from week 5 to 40 in comparison to non-pregnant women [63, 64]. Additionally, testosterone decreased uterine blood flow to the placenta [65]. It is interesting to note that the free androgen index fell rapidly from weeks 5-21, plateauing at week 21 and rising marginally at 40 weeks [63]. Interestingly, aberrant placental function has not been described in the pregnancies of CAIS fetuses, suggesting that maternal androgen signalling may be sufficient to mediate any required androgen-regulated angiogenesis during placental 
125 development. Excess testosterone during pregnancy can negatively impact placental 126 angiogenesis [66, 67]. For example, androgen levels are higher in pregnant women with 127 polycystic ovary syndrome (PCOS) as compared with normal pregnancy [68]. Free androgen 128 index, testosterone, androstenedione, and dehydroepiandrosterone (DHEA) levels were all 129 increased in PCOS pregnancies compared with normal pregnancies during weeks 22 to 28 , but 130 not earlier in pregnancy (weeks 10 - 16) [68]. Despite differing circulating levels of androgens 131 during pregnancy, fetal virilisation was not observed. However this was likely due to fetal 132 virilisation occurring between weeks 8 and 13 of gestation, whilst the increased levels of 133 androgens were observed at week $16[63,64,68]$. The placenta also expresses aromatase 134 which rapidly converts androgens to estrogen $[68,69]$. This could explain why the fetus is not 135 affected by virilisation in normal pregnancy. No associations have been observed between 136 concentrations of testosterone and the sex of the baby in pregnant vs non-pregnant women 137 [63]. Levels of DHEA, androstenedione or testosterone in normal pregnant women vs pregnant 138 PCOS women were also not dependent on the sex of the baby [68].

140 Increased first trimester total testosterone levels in women was also shown to be an 141 independent predictor of gestational diabetes mellitus (GDM) [70]. Increased androgen 142 sensitivity in the human GDM placenta compared to healthy placentas has also been reported 143 [69] as have increased $A R$ mRNA and protein levels of in GDM placentae. In contrast 144 aromatase protein expression was decreased in GDM placentas compared with healthy 145 placentas, which was suggested to lead to reduced conversion of testosterone to estrogen [69]. 146 Placentas from women with GDM also showed decreased human placental mRNA and protein 147 expression of VEGFR2 and VEGFA compared to control placentas. Qualitative analysis of 148 immunohistochemical localization reported that although mRNA and protein levels were lower, 
and immune-staining was weaker, VEGFR2 and VEGFA were expressed in the same cells and localities within the GDM and control placentas [67].

There is evidence that suggests the mechanisms of angiogenesis are similar in the placenta and prostate cancer. Evidence from early studies on first generation angiogenesis inhibitors such as TNP-470, implicated impaired angiogenesis as a contributing factor in intrauterine growth restriction of the fetus [71]. TNP-470 was shown to have an effect on human PCa cells and a number of tumors in patients $[72,73]$. Similarly, the endogenous angiogenesis inhibitor, angiostatin4.5, has also shown activity in tumors [74]. Like TNP-470, angiostatin4.5 also reduces murine placental angiogenesis and with the offspring showing skeletal growth delays [75]. Maliqueo and colleagues have recently provided a comprehensive review of the diverse roles of the sex steroids in the regulation of the uterine-placental vasculature [76]. Yet current understanding of the role of androgen signalling in placental development and particularly its potential role in regulating angiogenesis in the placenta, is incomplete. Androgens are known to stimulate proliferation of human umbilical vein endothelial cells (HUVECs) [77], indicating a role for androgens during pregnancy. Interestingly, this androgen effect on HUVEC function was not sex dependent. There is also evidence from rat models that excess androgen reduces uterine blood flow and increases maternal and adult offspring blood pressure, by a convergence of mechanisms involving angiotensin II, reduced eNOS activity, a consequent reduction in NO production and AR activation of protein kinase C (PKCD) [78-81]. Furthermore, increased testosterone results in elevated expression of hypoxia related genes including hypoxia inducible factor $1 \alpha$ (HIF1 $\alpha$ ) [80], an established positive regulator of VEGFA [82]. VEGFA is believed to play important roles in the earliest stages of embryonic implantation [83]. Yet the potential role of androgens in regulating VEGFAand angiogenesis in the placenta remains poorly defined. But in a recent ovine study examining the effects of testosterone on the placenta, VEGFA 
174 expression was observed to be androgen responsive. Indeed AR and the KDM1A coregulator 175 are recruited to an androgen response element (ARE) in the ovine VEGFA locus [25]. On 176 gestational day 90, placental VEGFA mRNA, placental VEGFA and AR protein levels increased 177 in testosterone-treated ewes compared with control placentas [25].

178 Beyond androgen regulation of VEGFAin angiogenesis [35, 54], there is also evidence for a role 179 for androgens in regulation of the Slt/Robo pathway [84]. The slits(1-3) are secreted 180 glycoproteins act as ligands for the Robos(1-4) transmembrane receptors. In one recent study, 181 expression of Slit and Robo mRNA was compared in normal and preeclamptic (characterised by 182 impaired angiogenesis and hypoxia) human placental tissue specimens [1]. Robo1 and Robo4 183 were shown to have significantly higher expression in pre-eclamptic as compared to healthy 184 tissue [85]. Additionally, hypoxia was shown to increase expression of Slit 2 in BeWo 185 choriocarcinoma cells and Robo1 and 4 and Slit 3 in human umbilical vein endothelial cells 186 (HUVEC) cells. Robo4 is a vascular specific and its activation by Slit2 has been shown in vitro 187 to inhibit mouse lung endothelial cell migration, tube formation and permeability induced by vascular endothelial growth factor (VEGF)-165 [85]. Conversely, human malignant melanoma 189 cells found to be expressing Slit2 were shown to induce angiogenesis in a xenograft animal 190 model [86]. This effect was reversed, and tumour growth impeded, by Robo1 blocking 191 antibodies or soluble Robo1 receptor. Slit/Robo signalling is implicated in multiple, often 192 contradictory, ways in several cancers relating to invasion, migration and apoptosis as well as 193 angiogenesis (Gara et al., 2015). In most cases the Slits and Robos are under expressed due 194 to promoter hypermethylation. Indeed there is evidence that androgen excess during pregnancy 195 can reduce Robo1 expression [84]. One consequence of this would be to impact angiogenesis.

197 Human trophoblast cells isolated at late stage pregnancy have been shown to express the 198 angiogenesis inhibitor, pigment epithelium-derived factor (PEDF), at higher levels than those 
from early pregnancy [87]. Additionally, only late stage pregnancy derived cells were capable of reducing angiogenesis of human placental endothelial cells. This anti-angiogenic effect could be

201 reduced with the addition of a PEDF blocking antibody. Recombinant PEDF was also shown to 202 induce an anti-angiogenic effect through inhibiting VEGFAsignalling. This suggests PDGF acts 203 in a paracrine manner to slow angiogenesis in the latter stages of pregnancy. Expression of 204 PEDF has also been shown to be reduced in PCa as compared to healthy control [88]. 205 However, there is evidence that androgen can both activate [89] and reduce [88] PEDF 206 expression in testicular peritubular cells and PCa respectively. Whether androgens regulate 207 PEDF in the placenta remains unknown.

209 It is also worth noting that whilst the placenta is undergoing angiogenesis and remodelling, so is 210 the maternal endometrium. The imbalance of pro- and anti-angiogenic factors has also been 211 shown to play a major role in disorders such as preeclampsia, where vascular disruption is 212 evident in both the placenta and maternal endothelium during this essential vascular 213 remodelling period [90, 91]. A number of studies have indicated that a key component of 214 circulating angiogenesis inhibitors is whether or not the vascular endothelial cells are quiescent 215 or activated and therefore expressing Fas at higher levels [92].

\section{Conclusion}

219 In this review we have discussed the current understanding of androgen signalling and how this 220 relates to angiogenesis in placental and cancer contexts. Previous studies have reported 221 changes in androgen levels during pregnancy and in pathogenic processes including PCOS and 222 GDM which are associated with concomitant changes in placental angiogenesis. However, 223 further work is required to elucidate the complex role of androgens and their metabolites in 
224 placental angiogenesis and development. The extensive repertoire of pharmacological inhibitors

225 of androgen signalling developed for PCa represent excellent tools to interrogate the androgen

226 signalling pathway in placental development. The availability of potent pharmacological agents

227 which can inhibit androgen synthesis (abiraterone) and conversion to estrogen (aromatase

228 inhibitors), coupled with AR-antagonists such as bicalutamide and enzalutamide (Figure 2),

229 afford the potential to further delineate the complex roles of androgens in placental

230 angiogenesis in animal models. Such approaches will also help advance understanding of the

231 life-long consequences of deregulated androgen signalling in utero.

\section{Acknowledgements}

234 The authors gratefully acknowledge the support of the University of Nottingham, Prostate 235 Cancer UK (NPM, DMH, SdB) and the BBSRC University of Nottingham Doctoral Training 236 Programme BB/J014508/1 and the School of Veterinary Medicine and Science, University of

237 Nottingham (NPM, CSR, DMH, VM, JW, DH, JL, EL). RRM and AAR were supported by 238 Program of Competitive Growth of Kazan Federal University, Russian Federation. 
Figure 1. (A) Crystal structure (PDB: 2AO6) of the AR ligand binding domain in complex with agonist R1881 and the LXXLL motif derived from SRC2/TIF2/NCOA2 [93]. The LBD is

242 represented in cartoon format (green) and shows the three layer antiparallel alpha-helical

243 sandwich conformation typical of NRs. The SRC2/TIF2/NCOA2 coactivator peptide is shown in

244 yellow and adopts an alpha helical conformation. Conserved leucine residues are shown in cyan

245 and contact the cofactor binding cleft on the LBD surface. The ligand R1881 is shown in red

246 with the ligand binding pocket. (B) Crystal structure (PDB: 1R4I) of the rat AR DNA binding

247 domain (DBD) bound to the direct repeat of the hexamer AGAACA as a direct repeat, separated

248 by thee nucleotides (DR3). [94]. The double stranded DNA duplex is shown in wireframe. The

249 DBD dimer is represented in cartoon format (green) and zinc atoms are portrayed as grey

250 spheres. The DBD monomers adopt alpha-helical conformations of which one these, the DNA

251 recognition helix, contacts specific bases and sugar-phosphate backbone of the 'response

252 element'. Interactions between the DBD monomers stabilise the dimer.

Figure 2. Androgen deprivation therapies are important treatment approaches for advanced prostate cancer. Abiraterone blocks adrenal and gonadal androgen biosynthesis by inhibiting 255 the Cyp17/17-a-hydroxylase/C17,20 lyase enzyme. Flutamide, bicalutamide and enzalutamide 256 block androgen signalling by acting as AR antagonists. ARN-509, also termed JNJ-56021927 is 257 in clinical phase III trials for advanced PCa (clinicaltrials.gov accessions: NCT02772588, NCT02489318, NCT02123758, NCT02578797, NCT01946204, NCT01790126, NCT01792687, 259 NCT02106507, accessed November 10, 2016).

260 Figure 3. Evaluation of the expression of vascular endothelial growth factor (VEGF-A) in 261 prostate cancer specimens as previously reported (Wegiel et al., 2008). Representative staining 262 examples are provided for benign prostate hyperplasia (BPH), low and high grade malignant 263 prostate tissue. Reproduced with permission from Kashyap et al [54] in Molecular Oncology, 2642013 Jun;7(3):555-66. doi: 10.1016/j.molonc.2013.01.003; Elsevier. 
266 [1] Liao WX, Laurent LC, Agent S, Hodges J and Chen DB. Human placental expression of SLIT/ROBO signaling cues: effects of preeclampsia and hypoxia. Biol Reprod. 2012;86(4):111. [2] Levine RJ, Maynard SE, Qian C, Lim KH, England LJ, Yu KF, Schisterman EF, Thadhani R, Sachs BP, Epstein FH, Sibai BM, Sukhatme VP and Karumanchi SA. Circulating angiogenic factors and the risk of preeclampsia. The New England journal of medicine. 2004;350(7):672-83. methylation and expression patterns of genes regulating placental angiogenesis in preterm pregnancy. Reprod Sci. 2014;21(12):1508-17.

[4] Hughes IA, Davies JD, Bunch TI, Pasterski V, Mastroyannopoulou K and MacDougall J. Androgen insensitivity syndrome. Lancet. 2012;380(9851):1419-28.

[5] de Brot S, Ntekim A, Cardenas R, James V, Allegrucci C, Heery DM, Bates DO, Odum N, Persson JL and Mongan NP. Regulation of vascular endothelial growth factor in prostate cancer. Endocrine-related cancer. 2015;22(3):R107-23.

[6] Randall VA. Role of 5 alpha-reductase in health and disease. Bailliere's clinical endocrinology and metabolism. 1994;8(2):405-31.

[7] Bellino FL, Gilani SS, Eng SS, Osawa Y and Duax WL. Active-site-directed inactivation of aromatase from human placental microsomes by brominated androgen derivatives. Biochemistry. 1976;15(21):4730-6.

[8] Nussey SS and Whitehead SA. Endocrinology: an integrated approach 2013: CRC Press.

[9] Baker ME. Albumin, steroid hormones and the origin of vertebrates. The Journal of endocrinology. 2002;175(1):121-7.

[10] Rosner W, Hryb DJ, Khan MS, Nakhla AM and Romas NA. Sex hormone-binding globulin: anatomy and physiology of a new regulatory system. The Journal of steroid biochemistry and molecular biology. 1991;40(4-6):813-20. generates androgens de novo. The Journal of clinical endocrinology and metabolism. 2011;96(5):138592.

[12] Ito K, Suzuki T, Akahira J, Moriya T, Kaneko C, Utsunomiya H, Yaegashi N, Okamura K and Sasano H. Expression of androgen receptor and 5alpha-reductases in the human normal endometrium and its disorders. International journal of cancer Journal international du cancer. 2002;99(5):652-7.

[13] Cloke B, Huhtinen K, Fusi L, Kajihara T, Yliheikkila M, Ho KK, Teklenburg G, Lavery S, Jones MC, Trew G, Kim JJ, Lam EW, Cartwright JE, Poutanen $\mathrm{M}$ and Brosens JJ. The androgen and progesterone receptors regulate distinct gene networks and cellular functions in decidualizing endometrium. Endocrinology. 2008;149(9):4462-74.

[14] Horie K, Takakura K, Imai K, Liao S and Mori T. Immunohistochemical localization of androgen receptor in the human endometrium, decidua, placenta and pathological conditions of the endometrium. Human reproduction. 1992;7(10):1461-6.

[15] Germain P, Staels B, Dacquet C, Spedding M and Laudet V. Overview of nomenclature of nuclear receptors. Pharmacological reviews. 2006;58(4):685-704.

[16] Simental JA, Sar M, Lane MV, French FS and Wilson EM. Transcriptional activation and nuclear targeting signals of the human androgen receptor. Journal of Biological Chemistry. 1991;266(1):510-8.

[17] Huang P, Chandra V and Rastinejad F. Structural overview of the nuclear receptor superfamily: insights into physiology and therapeutics. Annual review of physiology. 2010;72:247.

310

[18] Rastinejad F. Retinoid $X$ receptor and its partners in the nuclear receptor family. Current opinion in structural biology. 2001;11(1):33-8. 
[19] Wärnmark A, Treuter E, Wright AP and Gustafsson J-A. Activation functions 1 and 2 of nuclear 2003;17(10):1901-9. [20] O'Malley BW, Malovannaya A and Qin J. Minireview: nuclear receptor and coregulator proteomics-2012 and beyond. Mol Endocrinol. 2012;26(10):1646-50.

[21] Metivier R, Penot G, Hubner MR, Reid G, Brand H, Kos M and Gannon F. Estrogen receptor-alpha directs ordered, cyclical, and combinatorial recruitment of cofactors on a natural target promoter. Cell. 2003;115(6):751-63.

[22] Rosenfeld MG, Lunyak VV and Glass CK. Sensors and signals: a coactivator/corepressor/epigenetic code for integrating signal-dependent programs of transcriptional response. Genes \& development. 2006;20(11):1405-28.

[23] Eberharter A and Becker PB. Histone acetylation: a switch between repressive and permissive chromatin. EMBO reports. 2002;3(3):224-9.

[24] Legube $G$ and Trouche D. Regulating histone acetyltransferases and deacetylases. EMBO reports. 2003;4(10):944-7.

[25] Cleys ER, Halleran JL, Enriquez VA, da Silveira JC, West RC, Winger QA, Anthony RV, Bruemmer JE, Clay CM and Bouma GJ. Androgen Receptor and Histone Lysine Demethylases in Ovine Placenta. PloS one. 2015;10(2):e0117472.

[26] Cai C, He HH, Chen S, Coleman I, Wang H, Fang Z, Chen S, Nelson PS, Liu XS and Brown M. Androgen receptor gene expression in prostate cancer is directly suppressed by the androgen receptor through recruitment of lysine-specific demethylase 1. Cancer cell. 2011;20(4):457-71.

[27] Berglund A, Johannsen TH, Stochholm K, Viuff MH, Fedder J, Main KM and Gravholt CH. Incidence, prevalence, diagnostic delay, and clinical presentation of female $46, \mathrm{XY}$ disorders of sex development. The Journal of clinical endocrinology and metabolism. 2016:jc20162248.

[28] Hiort O. Clinical and molecular aspects of androgen insensitivity. 2013. pp. 33-40. Karger Publishers. [29] Tadokoro-Cuccaro R, Davies J, Mongan NP, Bunch T, Brown RS, Audi L, Watt K, McEwan IJ and Hughes IA. Promoter-dependent activity on androgen receptor $\mathrm{N}$-terminal domain mutations in androgen insensitivity syndrome. Sexual development : genetics, molecular biology, evolution, endocrinology, embryology, and pathology of sex determination and differentiation. 2014;8(6):339-49.

[30] Jaaskelainen J, Mongan NP, Harland S and Hughes IA. Five novel androgen receptor gene mutations associated with complete androgen insensitivity syndrome. Human mutation. 2006;27(3):291.

[31] Rosa S, Biason-Lauber A, Mongan NP, Navratil F and Schoenle EJ. Complete androgen insensitivity syndrome caused by a novel mutation in the ligand-binding domain of the androgen receptor: functional characterization. The Journal of clinical endocrinology and metabolism. 2002;87(9):4378-82.

[32] Mongan NP, Jaaskelainen J, Green K, Schwabe JW, Shimura N, Dattani M and Hughes IA. Two de novo mutations in the AR gene cause the complete androgen insensitivity syndrome in a pair of monozygotic twins. The Journal of clinical endocrinology and metabolism. 2002;87(3):1057-61.

[33] Gottlieb B, Beitel LK, Nadarajah A, Paliouras M and Trifiro M. The androgen receptor gene mutations database: 2012 update. Human mutation. 2012;33(5):887-94.

[34] Sarwar M, Semenas J, Miftakhova R, Simoulis A, Robinson B, Gjorloff Wingren A, Mongan NP, Heery DM, Johnsson H, Abrahamsson PA, Dizeyi N, Luo J and Persson JL. Targeted suppression of AR-V7 using PIP5K1alpha inhibitor overcomes enzalutamide resistance in prostate cancer cells. Oncotarget. 2016;7(39):63065-81.

[35] Nilsson EM, Laursen KB, Whitchurch J, McWilliam A, Odum N, Persson JL, Heery DM, Gudas L and Mongan NP. MiR137 is an androgen regulated repressor of an extended network of transcriptional coregulators. Oncotarget. 2015;6(34):35710-25. 
[36] Jiang W, Zhang J, Zhou Q, Liu S, Ni M, Zhu P, Wu Q, Li W, Zhang M and Xia X. Predictive value of GGN and CAG repeat polymorphisms of androgen receptors in testicular cancer: a meta-analysis. Oncotarget. 2016;7(12):13754-64.

[37] Kauffman EC, Robinson BD, Downes MJ, Powell LG, Lee MM, Scherr DS, Gudas LJ and Mongan NP. Role of androgen receptor and associated lysine-demethylase coregulators, LSD1 and JMJD2A, in localized and advanced human bladder cancer. Molecular carcinogenesis. 2011;50(12):931-44.

[38] Tarulli GA, Butler LM, Tilley WD and Hickey TE. Bringing androgens up a NOTCH in breast cancer. Endocrine-related cancer. 2014;21(4):T183-202.

[39] Elebro K, Borgquist S, Simonsson M, Markkula A, Jirstrom K, Ingvar C, Rose C and Jernstrom H. Combined Androgen and Estrogen Receptor Status in Breast Cancer: Treatment Prediction and Prognosis in a Population-Based Prospective Cohort. Clinical cancer research : an official journal of the American Association for Cancer Research. 2015;21(16):3640-50.

[40] Aleskandarany MA, Abduljabbar R, Ashankyty I, Elmouna A, Jerjees D, Ali S, Buluwela L, DiezRodriguez M, Caldas C, Green AR, Ellis IO and Rakha EA. Prognostic significance of androgen receptor expression in invasive breast cancer: transcriptomic and protein expression analysis. Breast cancer research and treatment. 2016;159(2):215-27.

[41] Kahl P, Gullotti L, Heukamp LC, Wolf S, Friedrichs N, Vorreuther R, Solleder G, Bastian PJ, Ellinger J, Metzger E, Schule R and Buettner R. Androgen receptor coactivators lysine-specific histone demethylase 1 and four and a half LIM domain protein 2 predict risk of prostate cancer recurrence. Cancer research. 2006;66(23):11341-7.

[42] Cai C, He HH, Chen S, Coleman I, Wang H, Fang Z, Nelson PS, Liu XS, Brown M and Balk SP. Androgen receptor gene expression in prostate cancer is directly suppressed by the androgen receptor through recruitment of lysine-specific demethylase 1. Cancer cell. 2011;20(4):457-71.

[43] Shi XB, Xue L, Zou JX, Gandour-Edwards R, Chen H and deVere White RW. Prolonged androgen receptor loading onto chromatin and the efficient recruitment of p160 coactivators contribute to androgen-independent growth of prostate cancer cells. The Prostate. 2008;68(16):1816-26.

[44] Zou JX, Zhong Z, Shi XB, Tepper CG, deVere White RW, Kung HJ and Chen H. ACTR/AIB1/SRC-3 and androgen receptor control prostate cancer cell proliferation and tumor growth through direct control of cell cycle genes. The Prostate. 2006;66(14):1474-86.

[45] Zhou XE, Suino-Powell KM, Li J, He Y, Mackeigan JP, Melcher K, Yong EL and Xu HE. Identification of SRC3/AIB1 as a preferred coactivator for hormone-activated androgen receptor. The Journal of biological chemistry. 2010;285(12):9161-71.

[46] Siegel RL, Miller KD and Jemal A. Cancer statistics, 2016. CA: a cancer journal for clinicians. 2016;66(1):7-30.

391 [47] Bourke L, Boorjian SA, Briganti A, Klotz L, Mucci L, Resnick MJ, Rosario DJ, Skolarus TA and Penson 392 DF. Survivorship and improving quality of life in men with prostate cancer. European urology. $393 \quad 2015 ; 68(3): 374-83$.

394 [48] Muralidhar V and Nguyen PL. Maximizing resources in the local treatment of prostate cancer: A 395 summary of cost-effectiveness studies. Urologic oncology. 2016.

[49] Boorjian SA, Eastham JA, Graefen M, Guillonneau B, Karnes RJ, Moul JW, Schaeffer EM, Stief C and Zorn KC. A critical analysis of the long-term impact of radical prostatectomy on cancer control and function outcomes. European urology. 2012;61(4):664-75.

[50] Heidenreich A, Bastian PJ, Bellmunt J, Bolla M, Joniau S, van der Kwast T, Mason M, Matveev V, Wiegel T, Zattoni F and Mottet N. EAU guidelines on prostate cancer. Part II: Treatment of advanced, relapsing, and castration-resistant prostate cancer. European urology. 2014;65(2):467-79.

[51] de Bono JS, Logothetis CJ, Molina A, Fizazi K, North S, Chu L, Chi KN, Jones RJ, Goodman OB, Jr., Saad F, Staffurth JN, Mainwaring P, Harland S, Flaig TW, Hutson TE, Cheng T, Patterson H, Hainsworth JD, Ryan CJ, Sternberg CN, Ellard SL, Flechon A, Saleh M, Scholz M, Efstathiou E, Zivi A, Bianchini D, Loriot Y, 
Chieffo N, Kheoh T, Haqq CM and Scher HI. Abiraterone and increased survival in metastatic prostate cancer. The New England journal of medicine. 2011;364(21):1995-2005.

[52] Marshall $S$ and Narayan P. Treatment of prostatic bleeding: suppression of angiogenesis by androgen deprivation. The Journal of urology. 1993;149(6):1553-4.

[53] Jain RK, Safabakhsh N, Sckell A, Chen Y, Jiang P, Benjamin L, Yuan F and Keshet E. Endothelial cell death, angiogenesis, and microvascular function after castration in an androgen-dependent tumor: role of vascular endothelial growth factor. Proceedings of the National Academy of Sciences of the United States of America. 1998;95(18):10820-5.

[54] Kashyap V, Ahmad S, Nilsson EM, Helczynski L, Kenna S, Persson JL, Gudas L and Mongan NP. The lysine specific demethylase-1 (LSD1/KDM1A) regulates VEGF-A expression in prostate cancer. Molecular oncology. 2013;7(3):555-66.

[55] Eisermann K, Broderick CJ, Bazarov A, Moazam MM and Fraizer GC. Androgen up-regulates vascular endothelial growth factor expression in prostate cancer cells via an Sp1 binding site. Molecular cancer. 2013;12:7.

[56] Orlandi P, Fontana A, Fioravanti A, Di Desidero T, Galli L, Derosa L, Canu B, Marconcini R, Biasco E, Solini A, Francia G, Danesi R, Falcone A and Bocci G. VEGF-A polymorphisms predict progression-free survival among advanced castration-resistant prostate cancer patients treated with metronomic cyclophosphamide. British journal of cancer. 2013;109(4):957-64.

[57] Kelly WK, Halabi S, Carducci M, George D, Mahoney JF, Stadler WM, Morris M, Kantoff P, Monk JP, Kaplan E, Vogelzang NJ and Small EJ. Randomized, Double-Blind, Placebo-Controlled Phase III Trial Comparing Docetaxel and Prednisone With or Without Bevacizumab in Men With Metastatic CastrationResistant Prostate Cancer: CALGB 90401. Journal of clinical oncology : official journal of the American Society of Clinical Oncology. 2012.

[58] McKay RR, Zurita AJ, Werner L, Bruce JY, Carducci MA, Stein MN, Heath El, Hussain A, Tran HT, Sweeney CJ, Ross RW, Kantoff PW, Slovin SF and Taplin ME. A Randomized Phase II Trial of Short-Course Androgen Deprivation Therapy With or Without Bevacizumab for Patients With Recurrent Prostate Cancer After Definitive Local Therapy. Journal of clinical oncology : official journal of the American Society of Clinical Oncology. 2016;34(16):1913-20.

[59] McKay RR, Gray KP, Hayes JH, Bubley GJ, Rosenberg JE, Hussain A, Kantoff PW and Taplin ME. Docetaxel, bevacizumab, and androgen deprivation therapy for biochemical disease recurrence after definitive local therapy for prostate cancer. Cancer. 2015;121(15):2603-11.

[60] Uhlen M, Fagerberg L, Hallstrom BM, Lindskog C, Oksvold P, Mardinoglu A, Sivertsson A, Kampf C, Sjostedt E, Asplund A, Olsson I, Edlund K, Lundberg E, Navani S, Szigyarto CA, Odeberg J, Djureinovic D, Takanen JO, Hober S, Alm T, Edqvist PH, Berling H, Tegel H, Mulder J, Rockberg J, Nilsson P, Schwenk JM, Hamsten M, von Feilitzen K, Forsberg M, Persson L, Johansson F, Zwahlen M, von Heijne G, Nielsen J and Ponten F. Proteomics. Tissue-based map of the human proteome. Science. 2015;347(6220):1260419.

[61] Macaulay JO, Warne GL and Krozowski ZS. Human placenta contains a high affinity R1881 binding site that is not the androgen receptor. Journal of steroid biochemistry. 1988;29(5):497-503.

[62] McCormick PD, Razel AJ, Spelsberg TC and Coulam CB. Evidence for an androgen receptor in the human placenta. American journal of obstetrics and gynecology. 1981;140(1):8-13.

[63] O'Leary P, Boyne P, Flett P, Beilby J and James I. Longitudinal assessment of changes in reproductive hormones during normal pregnancy. Clinical Chemistry. 1991;37(5):667-72.

[64] Castracane VD, Stewart DR, Gimpel T, Overstreet JW and Lasley BL. Maternal serum androgens in human pregnancy: early increases within the cycle of conception. Human reproduction. 1998;13(2):4604.

[65] Abbas A and Gupta S. The role of histone deacetylases in prostate cancer. Epigenetics. 2008;3(6):300-9. 
[66] Fornes R, Hu M, Maliqueo M, Kokosar M, Benrick A, Carr D, Billig H, Jansson T, Manni L and StenerVictorin E. Maternal testosterone and placental function: Effect of electroacupuncture on placental expression of angiogenic markers and fetal growth. Molecular and cellular endocrinology. 2016;433:111.

[67] Meng Q, Shao L, Luo X, Mu Y, Xu W, Gao L, Xu H and Cui Y. Expressions of VEGF-A and VEGFR-2 in placentae from GDM pregnancies. Reprod Biol Endocrin. 2016;14(1):61.

[68] Sir-Petermann T, Maliqueo M, Angel B, Lara H, Perez-Bravo F and Recabarren S. Maternal serum androgens in pregnant women with polycystic ovarian syndrome: possible implications in prenatal androgenization. Human Reproduction. 2002;17(10):2573-9.

[69] Uzelac P, Li X, Lin J, Neese L, Lin L, Nakajima S, Bohler H and Lei Z. Dysregulation of leptin and testosterone production and their receptor expression in the human placenta with gestational diabetes mellitus. Placenta. 2010;31(7):581-8.

[70] Gözükara YM, Aytan H, Ertunc D, Tok EC, Demirtürk F, Şahin Ş and Aytan P. Role of first trimester total testosterone in prediction of subsequent gestational diabetes mellitus. Journal of Obstetrics and Gynaecology Research. 2015;41(2):193-8.

[71] Rutland CS, Mukhopadhyay M, Underwood S, Clyde N, Mayhew TM and Mitchell CA. Induction of intrauterine growth restriction by reducing placental vascular growth with the angioinhibin TNP-470. Biol Reprod. 2005;73(6):1164-73.

[72] Castronovo $V$ and Belotti D. TNP-470 (AGM-1470): mechanisms of action and early clinical development. Eur J Cancer. 1996;32A(14):2520-7.

[73] Horti J, Dixon SC, Logothetis CJ, Guo Y, Reed E and Figg WD. Increased transcriptional activity of prostate-specific antigen in the presence of TNP-470, an angiogenesis inhibitor. Br J Cancer. 1999;79(910):1588-93.

[74] Soff GA, Wang H, Cundiff DL, Jiang K, Martone B, Rademaker AW, Doll JA and Kuzel TM. In vivo generation of angiostatin isoforms by administration of a plasminogen activator and a free sulfhydryl donor: a phase I study of an angiostatic cocktail of tissue plasminogen activator and mesna. Clin Cancer Res. 2005;11(17):6218-25.

[75] Rutland CS, Atkinson SD, Mukhopadhyay M, Jiang K, Soff GA, Mayhew TM and Mitchell CA. Thrombophilic-type placental pathologies and skeletal growth delay following maternal administration of angiostatin4.5 in mice. Biol Reprod. 2011;84(3):505-13.

[76] Maliqueo M, Echiburu B and Crisosto N. Sex Steroids Modulate Uterine-Placental Vasculature: Implications for Obstetrics and Neonatal Outcomes. Frontiers in physiology. 2016;7:152.

[77] Torres-Estay V, Carreno DV, Fuenzalida P, Watts A, San Francisco IF, Montecinos VP, Sotomayor PC, Ebos J, Smith GJ and Godoy AS. Androgens modulate male-derived endothelial cell homeostasis using androgen receptor-dependent and receptor-independent mechanisms. Angiogenesis. 2016.

[78] Chinnathambi V, Balakrishnan M, Ramadoss J, Yallampalli C and Sathishkumar K. Testosterone alters maternal vascular adaptations: role of the endothelial NO system. Hypertension. 2013;61(3):647-54.

[79] Blesson CS, Chinnathambi V, Hankins GD, Yallampalli C and Sathishkumar K. Prenatal testosterone exposure induces hypertension in adult females via androgen receptor-dependent protein kinase Cdelta-mediated mechanism. Hypertension. 2015;65(3):683-90.

[80] Chinnathambi V, Blesson CS, Vincent KL, Saade GR, Hankins GD, Yallampalli C and Sathishkumar K. Elevated testosterone levels during rat pregnancy cause hypersensitivity to angiotensin II and attenuation of endothelium-dependent vasodilation in uterine arteries. Hypertension. 2014;64(2):40514.

[81] Gopalakrishnan K, Mishra JS, Chinnathambi V, Vincent KL, Patrikeev I, Motamedi M, Saade GR, Hankins GD and Sathishkumar K. Elevated Testosterone Reduces Uterine Blood Flow, Spiral Artery Elongation, and Placental Oxygenation in Pregnant Rats. Hypertension. 2016;67(3):630-9. 
[82] Gudas LJ, Fu L, Minton DR, Mongan NP and Nanus DM. The role of HIF1alpha in renal cell carcinoma tumorigenesis. J Mol Med (Berl). 2014;92(8):825-36.

[83] Hannan NJ, Paiva P, Meehan KL, Rombauts L, Gardner DK and Salamonsen LA. Analysis of fertilityrelated soluble mediators in human uterine fluid identifies VEGFAas a key regulator of embryo implantation. Endocrinology. 2011;152(12):4948-56.

[84] Hogg K, McNeilly AS and Duncan WC. Prenatal androgen exposure leads to alterations in gene and protein expression in the ovine fetal ovary. Endocrinology. 2011;152(5):2048-59.

[85] Jones CA, London NR, Chen H, Park KW, Sauvaget D, Stockton RA, Wythe JD, Suh W, LarrieuLahargue F, Mukouyama YS, Lindblom P, Seth P, Frias A, Nishiya N, Ginsberg MH, Gerhardt H, Zhang K and Li DY. Robo4 stabilizes the vascular network by inhibiting pathologic angiogenesis and endothelial hyperpermeability. Nature medicine. 2008;14(4):448-53.

[86] Wang B, Xiao Y, Ding BB, Zhang N, Yuan X, Gui L, Qian KX, Duan S, Chen Z, Rao Y and Geng JG. Induction of tumor angiogenesis by Slit-Robo signaling and inhibition of cancer growth by blocking Robo activity. Cancer cell. 2003;4(1):19-29.

[87] Loegl J, Nussbaumer E, Hiden U, Majali-Martinez A, Ghaffari-Tabrizi-Wizy N, Cvitic S, Lang I, Desoye $\mathrm{G}$ and Huppertz B. Pigment epithelium-derived factor (PEDF): a novel trophoblast-derived factor limiting feto-placental angiogenesis in late pregnancy. Angiogenesis. 2016;19(3):373-88.

[88] Doll JA, Stellmach VM, Bouck NP, Bergh AR, Lee C, Abramson LP, Cornwell ML, Pins MR, Borensztajn $\mathrm{J}$ and Crawford SE. Pigment epithelium-derived factor regulates the vasculature and mass of the prostate and pancreas. Nature medicine. 2003;9(6):774-80.

[89] Windschuttl S, Kampfer C, Mayer C, Flenkenthaler F, Frohlich T, Schwarzer JU, Kohn FM, Urbanski H, Arnold GJ and Mayerhofer A. Human testicular peritubular cells secrete pigment epithelium-derived factor (PEDF), which may be responsible for the avascularity of the seminiferous tubules. Scientific reports. 2015;5:12820.

[90] Kurlak LO, Mistry HD, Cindrova-Davies T, Burton GJ and Broughton Pipkin F. Human placental reninangiotensin system in normotensive and pre-eclamptic pregnancies at high altitude and after acute hypoxia-reoxygenation insult. J Physiol. 2016;594(5):1327-40.

[91] Powe CE, Levine RJ and Karumanchi SA. Preeclampsia, a disease of the maternal endothelium: the role of antiangiogenic factors and implications for later cardiovascular disease. Circulation. 2011;123(24):2856-69.

[92] Tiwari M. Apoptosis, Angiogenesis and Cancer Therapies. Journal of Cancer Therapeutics and Research. 2012;1(1).

[93] He B, Gampe RT, Jr., Kole AJ, Hnat AT, Stanley TB, An G, Stewart EL, Kalman RI, Minges JT and Wilson EM. Structural basis for androgen receptor interdomain and coactivator interactions suggests a transition in nuclear receptor activation function dominance. Molecular cell. 2004;16(3):425-38.

[94] Shaffer PL, Jivan A, Dollins DE, Claessens F and Gewirth DT. Structural basis of androgen receptor binding to selective androgen response elements. Proceedings of the National Academy of Sciences of the United States of America. 2004;101(14):4758-63. 


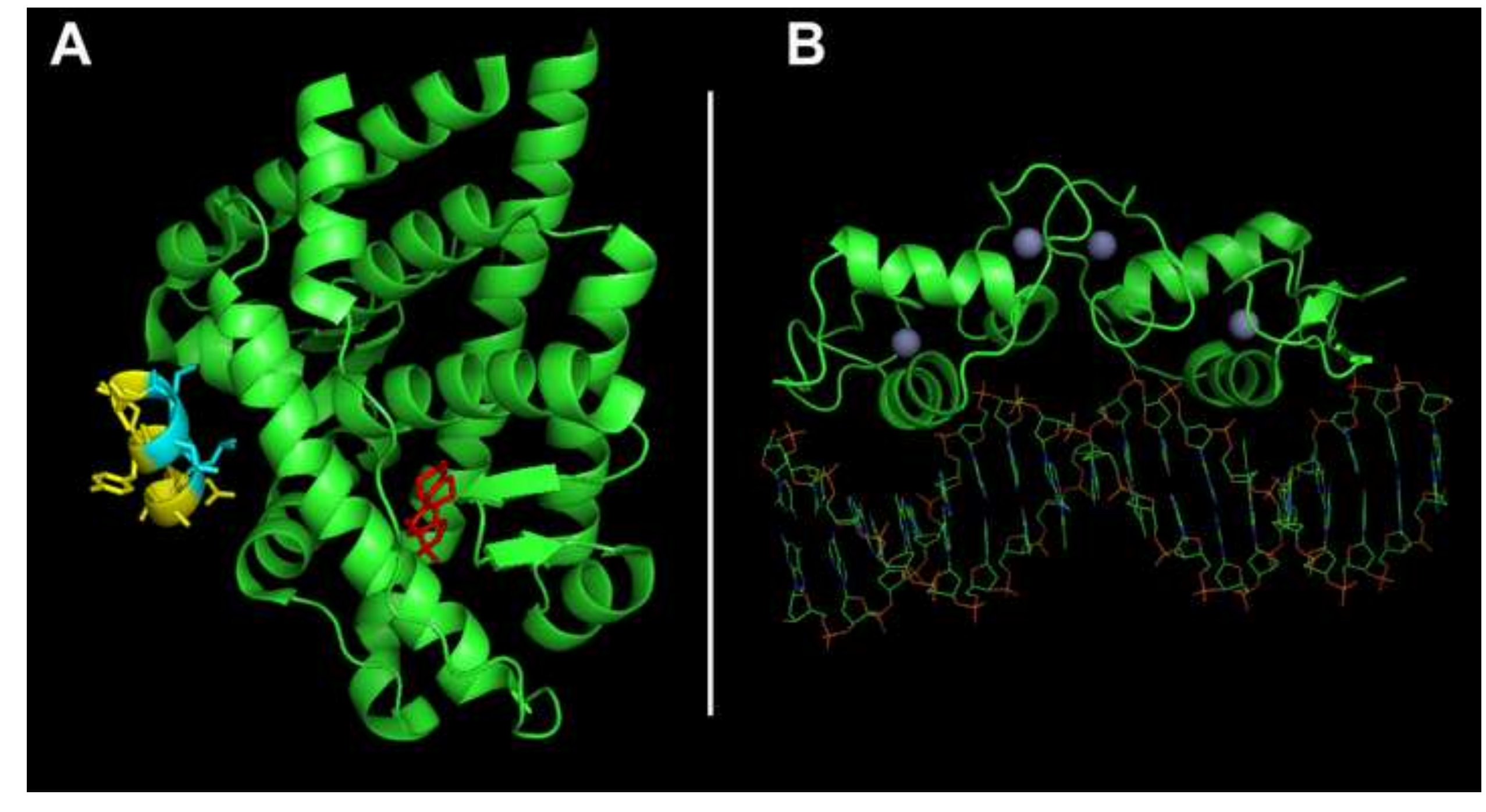

\section{Click here to download high resolution image}




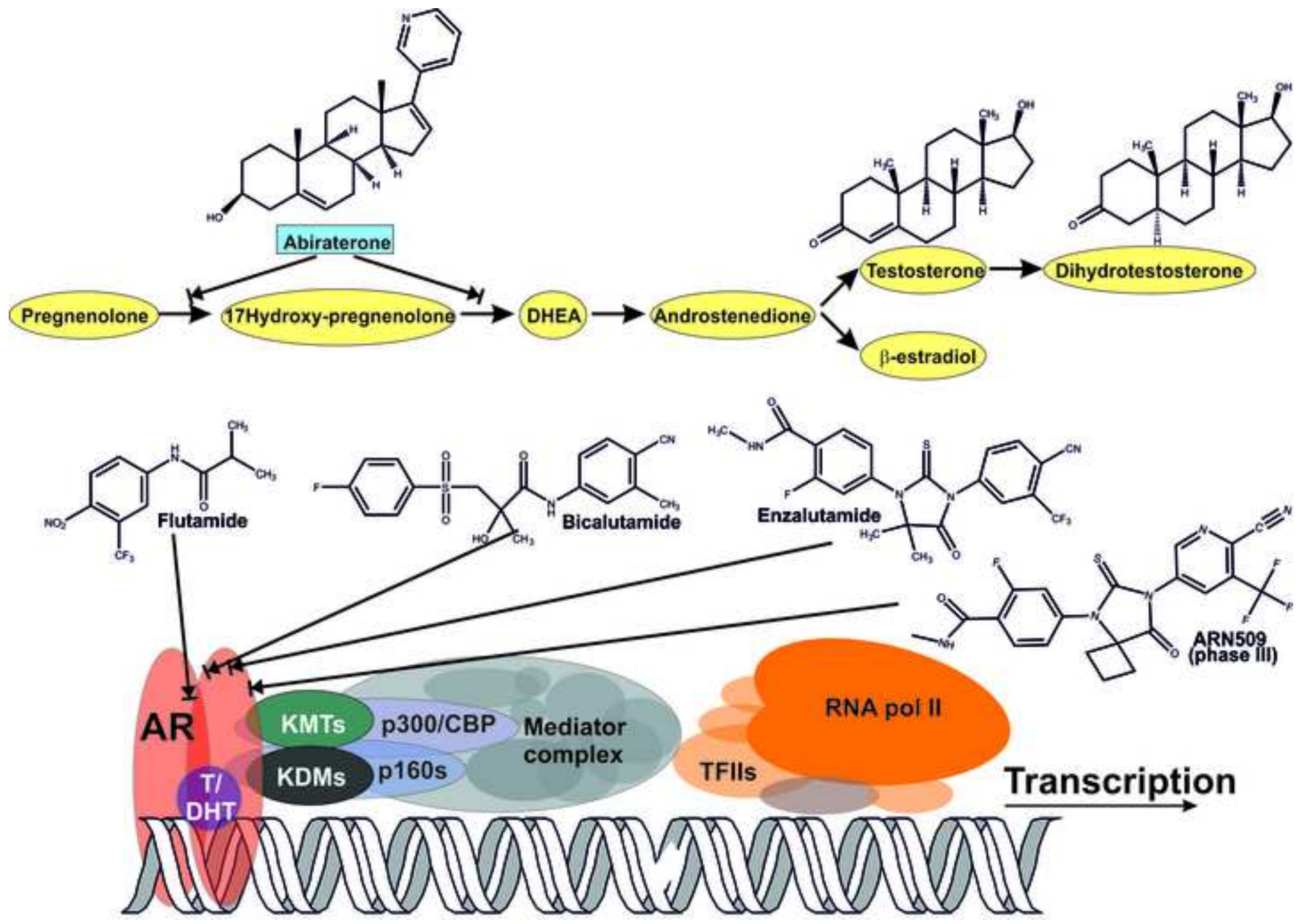




\section{VEGF}

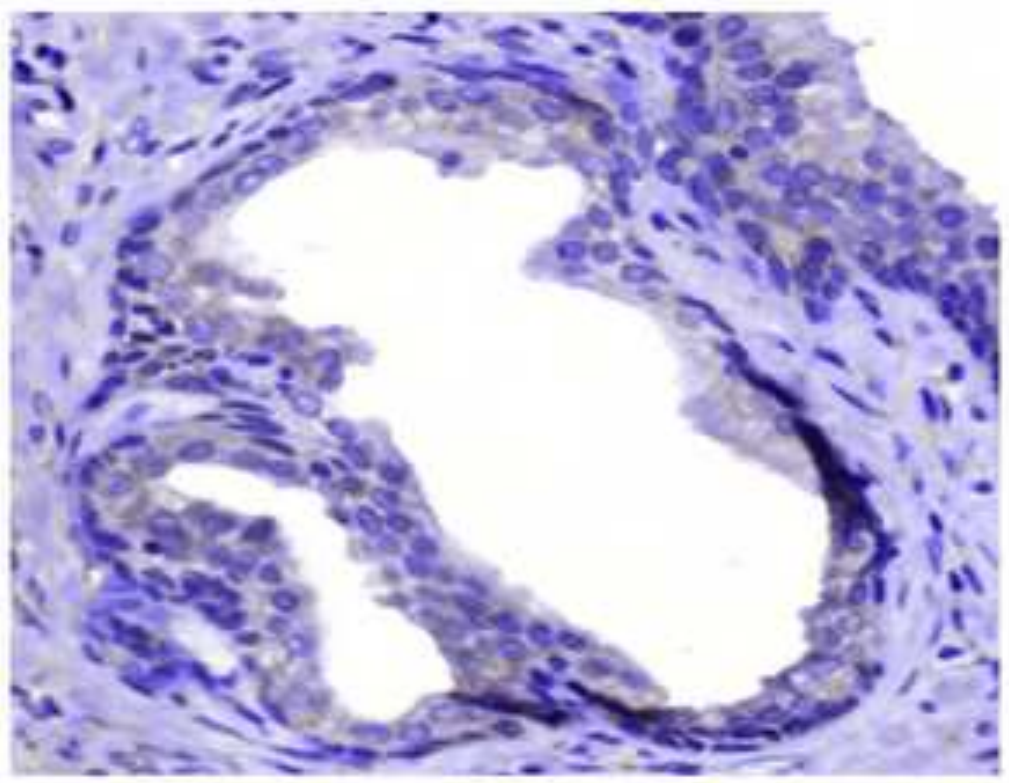

BPH

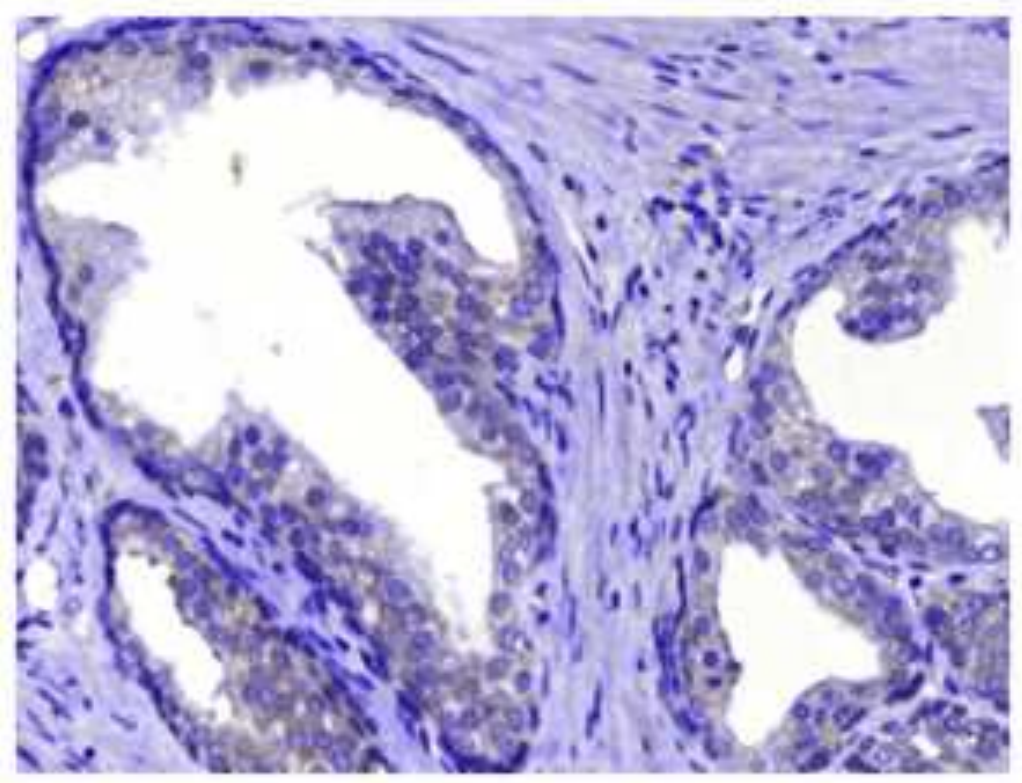

\section{Low}

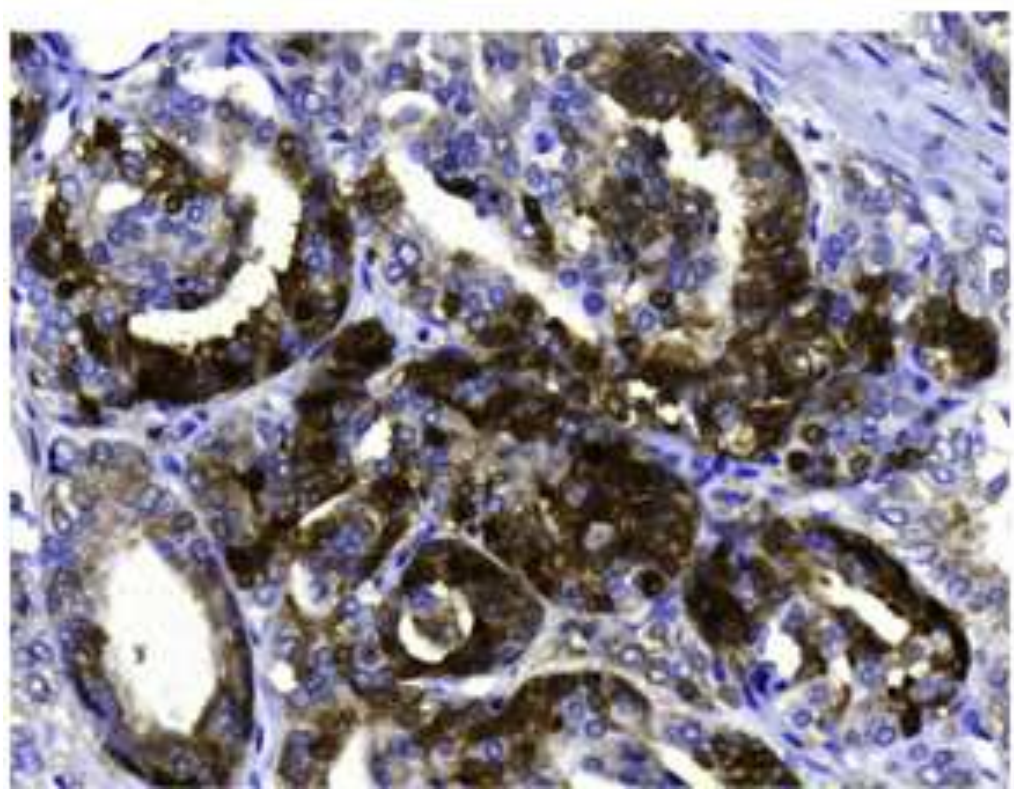

\section{High}

